\title{
Bayesian Multilevel Analysis of Determinants of Acute Respiratory Infection in Children Under The Age of Five Years in Ethiopia
}

Tilahun Ferede Asena ( $\nabla$ feredetilahun14@gmail.com )

Arba Minch University https://orcid.org/0000-0001-9282-9809

Amanuel Mengistu Merera

Mizan-Tepi University

Mebratu Alemu Senbeta

Arba Minch University

Research article

Keywords: Acute Respiratory Infections, Bayesian Multilevel, MCMC

Posted Date: July 13th, 2021

DOI: https://doi.org/10.21203/rs.3.rs-120356/v2

License: (1) (i) This work is licensed under a Creative Commons Attribution 4.0 International License.

Read Full License

Version of Record: A version of this preprint was published at BMC Pediatrics on March 10th, 2022. See the published version at https://doi.org/10.1186/s12887-022-03187-4. 


\title{
Bayesian Multilevel Analysis of Determinants of Acute Respiratory Infection in Children under the Age of Five Years in Ethiopia
}

\author{
Amanuel Merera ${ }^{1}$, Tilahun Asena ${ }^{2 *}$, Mebratu Senbeta ${ }^{3}$ \\ ${ }^{1}$ Department of Statistics, Mizan-Tepi University, Mizan-Tepi, Ethiopia \\ ${ }^{2}$ Department of Statistics, Arba Minch University, Arba Minch, Ethiopia \\ ${ }^{3}$ Department of Economics, Arba Minch University, Arba Minch, Ethiopia \\ *Email of corresponding author: feredetilahun14@gmail.com
}

\section{Abstract}

Background: Acute respiratory tract infection (ARI) is one of the causes for morbidity and mortality in children under the age of 5 years in the world. Pneumonia, which is caused by respiratory tract infection, accounts for approximately 1.9 million deaths globally in children under the age of five years. Among these deaths majority occurs in the developing world. The share for low and middle-income countries takes the highest indeed. In Ethiopia, the prevalence rate of ARI was 7\% according to 2016 EDHS estimates.

Method: Bayesian multilevel approach was employed to assess factors associated with the prevalence of ARI among under-five children in Ethiopia. The data was collected from 10,641 children under the age of five years out of which 9,918 children were considered in this study.

Result: The ARI prevalence rate for children under five years was estimated as $8.4 \%$, which was slightly higher than the estimated prevalence level of the country. The highest proportion of the prevalence of ARI was observed for children whose mothers had no education. The major health, environmental and nutritional related background characteristics of the proportion of children who had ARI varied from one region to another. The highest prevalence of ARI was observed in Tigray (15.31\%) followed by Oromia (14.40\%) as opposed to the low prevalence which was recorded in Benishangul Gumuz (2.58\%). The utilization of vitamin A was analyzed and the results shows that about $43.10 \%$ who received vitamin A had the lowest proportion on the prevalence of ARI (7.75\%) 
compared to not having vitamin A. About $11.13 \%$ of under-five children had Diarrhea with the highest prevalence of ARI (24.64\%) and the highest prevalence of ARI was observed for the child whose source of drinking water were unprotected/unimproved $(9.39 \%)$.

Conclusion: The age of the child, household wealth index, mother educational level, and vitamin A supplement, history of diarrhea, maternal work, stunting and source of drinking water was found to be significantly affecting the prevalence of ARI among children under five years. Furthermore, the study revealed that there is a significant variation of incidence of ARI between and within the regions of Ethiopia. Attention should be given to those predictor variables while planning to increase the health status of children in Ethiopia.

Keywords: Acute Respiratory Infections, Bayesian Multilevel, MCMC

\section{Background}

Acute respiratory tract infection is one of the causes for morbidity and mortality in children under the age of 5 years in the world. Pneumonia caused by respiratory tract infection is the main reason for about fifteen percent deaths in children under the age of 5 years globally. Sub-Saharan Africa takes about half of the shares of these deaths [1].

Globally, lower respiratory infections attributes to the fifth leading cause of death and the leading cause of death in children below five years of age, which counts about 2 to 6 million deaths in the world [2]. In comparison to high-income countries, low and middleincome countries takes the highest burden of high incidence and prevalence of ARIs. According to WHO, the annual number of ARI-related deaths in children less than five years old (excluding death caused by measles, pertussis and neonatal deaths) were 2.1 million. 10.8 million Children die because of ARI each year. Estimates indicate that in the year 2000, about 1.9 million children died due to ARI, $70 \%$ of them in Africa and Southeast Asia [3].

Pneumonia is an infections of that inflames the air sacs in one or both lungs that account for approximately 1.9 million (1.6 - 2.2 million) deaths globally in children under the age of five years each year and $90 \%$ of which occur in the developing world [4]. The major cause of morbidity and mortality among children less than five years old children in low and middleincome countries is acute respiratory infections (ARIs). About 126 - 156 million cases of acute lower respiratory infections (ALRI) such as pneumonia and bronchitis occur worldwide 
each year in children leading to approximately 1.4 million deaths. More than $95 \%$ of these deaths occur in Africa and in South-East Asia [5, 6] and [7].

In 2016 children who died before reaching their fifth birthday is estimated to be 5.6 million [8]. Literatures suggest the main causes for deaths registered were due to lack of health care services, poverty and low levels of education in developing world. In developing world, the proportion of children who die from ARI is ten to fifty times more likely to than those living in developed countries [9]. Although Ethiopia achieved the fourth MDG target three years earlier by reducing under five mortality by $67 \%$ from the 1990 estimate, about 190, 000 children are still dying each year due to different causes. According to the WHO estimates, among the 2014 deaths recorded about $18 \%$ of mortalities are due to ARI for children below five years [10]. In Ethiopia, about $19 \%$ of the children had ARI in the preceding two weeks according to Integrated Community Case Management Survey in Amhara, SNNP, and Tigray Regions [11].

Based on the 2016 Ethiopia Demographic and Health Survey (EDHS), the prevalence of ARI was 7\% [12]. Several studies have been conducted and possible comparisons are so far made between the Bayesian and classical/frequents approaches for population and health survey studies $[13,14]$. Both approaches treat differently the behavior of a parameter. A parameter is treated as a fixed value in the frequents approach whereas as a random variable with its distribution in the Bayesian ideology [15]. The Bayesians gives the possibility of additional information that is external to the sample by incorporating the prior distributions to the likelihood $[16,17]$. The addition of this prior improves accuracy and credibility of the estimates.

Investigators across the globe employed different classical approaches to identify important risk factors of acute respiratory infections (ARIs) among under-five children [18, 19], which actually cannot be empowered to answer whether there were geographical variations or not. Although, classical technique fits the regression models by means of an iterative approach and in some cases, because of this iterative approach, convergence may be difficult to achieve. The robustness and accuracy of the results produced by Bayesian approach make its gain popularity in data analysis. The current study is thus to investigate factors associated with the prevalence of ARI morbidity among children under five years, and explore between and within regional variations of ARI in the country. 


\section{Methods}

\subsection{The Data}

The 2016 EDHS sample was selected by considering two-stage cluster design and census enumeration areas (EAs) were the sampling units for the first stage. The sample included 645EAs (202 in urban areas and 443 in rural areas). In the sampling procedure, households comprised the second stage of sampling. All women aged 15-49 years who had at least one child in the five years before the survey were eligible for participation. The sample for this study would be consisted of 10,641 under-five children, from which only 9,918 of them would be considered in this study.

\subsection{Multilevel Logistic Regression Model}

The multilevel logistic regression extends from single level logistic regression model by including random effects to the model [20]. Suppose we have data consisting of under-five children's, (level one) grouped into regions (level two). Let $Y_{i j}$ be the binary response for ARI among $i^{\text {th }}$ under five years old children in region $\mathrm{j}$ and $X_{i j}$ be an explanatory variable. We define the probability of the response equal to one $\pi_{i j}=P\left(y_{i j}=1\right)$ Where; $\pi_{i j}$ be modeled using a logit link function. The standard assumption is that $Y_{i j}$ has a Bernoulli distribution. Then, the two-level models are given by:

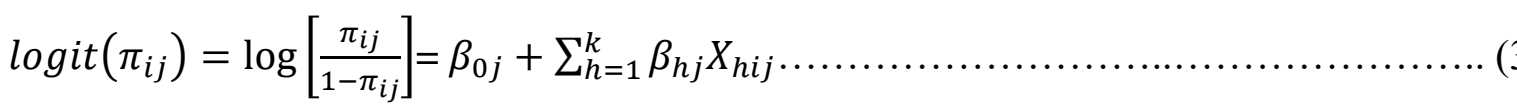

$$
\begin{aligned}
& i=1,2 \ldots \ldots n_{j}, h=1,2 \ldots \ldots \ldots . k, j=1,2, \ldots \ldots \ldots 11 \\
& \beta_{o j}=\beta_{o}+U_{o j}, \beta_{1 j}=\beta_{1}+U_{1 j}, \ldots, \beta_{k j}=\beta_{k}+U_{k j} \\
& \operatorname{logit}\left(\pi_{i j}\right)=\log \left[\frac{\pi_{i j}}{1-\pi_{i j}}\right]=\beta_{0}+\sum_{h=1}^{k} \beta_{h j} X_{h i j}+U_{o j}+\sum_{h=1}^{k} U_{h j} X_{h i j}
\end{aligned}
$$

$X_{i}=\left(X_{1 i j}, X_{2 i j}, \ldots \ldots \ldots X_{k i j}\right)$ represent the first and the second level covariates, for variable $\mathrm{k}\left(\beta=\beta_{o}, \beta_{1}, \ldots \ldots \beta_{k}\right)$ are the regression parameter coefficient $U_{0 j}, U_{1 j}, \ldots \ldots, U_{k j}$ is the random effect of the model parameter at level two. With the assumption $U_{h j}$, follows a normal distribution with mean zero and variance $\sigma_{u}^{2}$.

\subsection{Multilevel Analysis of Empty Model (Null Model)}

The empty two-level model for a binary outcome variable refers to a population of groups (level-two units, i.e. regions)) and specifies the probability distribution for group-dependent probabilities without considering further explanatory variables $[20,21]$. This model only 
contains random groups and random variation within groups. It can be expressed with logit link function as follows.

$$
\begin{aligned}
& \operatorname{logit}\left(\pi_{i j}\right)=\beta_{0}+U_{0 j} \\
& U_{0 j} \sim \operatorname{IID}\left(0, \sigma_{0}^{2}\right)
\end{aligned}
$$

Where $\beta_{0}$ indicates the population average of the transformed probability and $U_{0 j}$ is the random deviations from this average for region $\mathrm{j}$

The model decomposes the total variance into two-that of region and under five children, representing the between and within region variability's in the ARI of under five children. The interclass correlation (ICC) measures correlation between observations within cluster as:

$$
I C C=\frac{\sigma_{u}^{2}}{\sigma_{u}^{2}+\sigma_{e}^{2}}
$$

\subsection{Multilevel Analysis of Random Intercept Model}

In the random intercept model the intercept is the only random effect meaning that the groups differ with respect to the average value of the response variable, but the relation between explanatory and response variables cannot be differ between groups [20]. The random intercept model expresses the log odds, i.e the logit of $\pi_{i j}$, as a sum of linear functions of the explanatory variables. That is,

$$
\begin{array}{r}
\operatorname{logit}\left(\pi_{i j}\right)=\log \left[\frac{\pi_{i j}}{1-\pi_{i j}}\right]=\beta_{0 j}+\sum_{h=1}^{k} \beta_{h} X_{h i j} \ldots \ldots \ldots \ldots \ldots \ldots . . . . . . . . .11
\end{array}
$$

Where the intercept term $\beta_{0 j}$ is assumed to vary randomly and is given by the sum of an average intercept $\beta_{0}$ and group-dependent deviations; $\beta_{0 j}=\beta_{0}+U_{0 j}$.

As a result we have:

$$
\operatorname{logit}\left(\pi_{i j}\right)=\beta_{0}+\sum_{h=1}^{k} \beta_{h} X_{h i j}+U_{0 j}
$$

Solving for $\pi_{i j}$ :

$$
\pi_{i j}=\frac{e^{\beta_{0}+\sum_{h=1}^{k} \beta_{h} X_{h i j}+U_{0 j}}}{1+e^{\beta_{0}+\sum_{h=1}^{k} \beta_{h} X_{h i j}+U_{0 j}}} .
$$

Equation (10) does not include a level one residual because it is an equation for the probability $\pi_{i j}$ rather than for the outcome $Y_{i j}$, where $\beta_{0}+\sum_{h=1}^{k} \beta_{h} X_{h i j}$ is the fixed part of the model. The remaining $U_{0 j}$ is called the random or the stochastic part of the model $[20,21]$. It 
is assumed that the residual $U_{0 j}$ is mutually independent and normally distributed with mean zero and variance $\sigma_{u}^{2}$.

\subsection{Bayesian Multilevel Analysis of Random Coefficients Model}

In the random coefficient model, both the intercepts and slopes are allowed to differ across the regions. Consider a model with group-specific regression of logit of the success probability logit $\left(\pi_{i j}\right)$ on a single level -one explanatory variable $X$

$$
\operatorname{logit}\left(\pi_{i j}\right)=\log \left[\frac{\pi_{i j}}{1-\pi_{i j}}\right]=\beta_{0}+\sum_{h=1}^{k} \beta_{h} X_{h i j}+U_{0 j}+\sum_{h=1}^{k} U_{h j} x_{h i j}
$$

The term $\sum_{h=1}^{k} U_{h j} x_{h i j}$ can be regarded as a random interaction between group and the explanatory variables. This model implies that two random effects characterize the groups: their intercepts and their slopes. It assumes that for different groups, the pairs of random effects $\left(U_{0}, U_{h j}, h=1,2, \ldots, k\right)$ are independent and identical distributed. The random intercept variance, $\operatorname{Var}\left(U_{0 j}\right)=\sigma_{0}^{2}$, the random slope variance, $\operatorname{Var}\left(U_{1 j}\right)=\sigma_{1}^{2}$ and the covariance between the random effects $\operatorname{Cov}\left(U_{0 j} ; U_{1 j}\right)=\sigma_{01}$ are called variance components [20].

\subsection{Method of Parameter Estimation}

The models used in this paper are fitted using Markov Chain Monte Carlo (MCMC) based algorithms as implemented in the MLwiN. Starting values for the fixed parameters was estimated from simpler models using a maximum likelihood approach, penalized quasilikelihood (PQL) in MLwiN [22]. The simulated posterior distribution is then used to compute a point estimate and a confidence interval. The posterior distribution of $\theta$ is defined from Bayes' theorem as:

$$
P(\beta / \text { data }) / P(\text { data } / \beta) P(\beta)
$$

Here $P(\beta)$ is the prior distribution for the parameter vector $\beta$ and should represent all knowledge we have about $\beta$ prior to obtaining the data. In this study, we wish to express our prior ignorance in to the Bayesian system. This leads to non-informative priors. A noninformative prior distribution that is used to express complete ignorance of the value before the data is collected. 
The default prior distribution applied in MLwiN when MCMC is used are 'flat' or 'diffuse' priors for all parameters (21).The prior distributions for fixed effect parameter was $P(\beta) \sim$ uniform distributions $(1)$ and for random effect terms was, $P\left(1 / \sigma^{2}\right) \sim \operatorname{Gamma}(\alpha, \theta)$ where $\alpha$ and $\theta$ are fixed constant parameters.Let us denote the parameters $\beta_{0}, \beta_{1}, \ldots \ldots, \beta_{k}$ and $\Omega_{u}$ as prior distributions would be given as follows; $P\left(\beta_{0}\right) \propto 1, P\left(\beta_{1}\right) \propto$ $1, \ldots \ldots, P\left(\beta_{k}\right) \propto 1$ and $P\left(\Omega_{u}\right) \propto$ inverse-wishart $\left(\mathrm{m} * S_{u}, v\right)$ distribution. The parameter $\Omega_{u}$ is the variance-covariance matrices and $S_{u}$ is an estimate for the true value of $\Omega_{u}$ and $v$ is the number of row in the variance-covariance matrix.

The joint distribution of $n$ independent Bernoulli trials is the product of each Bernoullidensities, where the sum of independent and identically distributed Bernoulli trials has a Binomial distribution. Thus, the likelihood function is illustrated below as product of $n$ Bernoulli trials:

$L\left(\pi_{i j} / y_{i j}\right)=\prod_{i j}\left(\pi_{i j}\right)^{y i j}\left(1-\pi_{i j}\right)^{1-y_{i j}}$ and the logit functions are:

$$
\operatorname{logit}\left(\pi_{i j}\right)=\log \left[\frac{\pi_{i j}}{1-\pi_{i j}}\right]=\beta_{0 j}+\sum_{h=1}^{k} \beta_{h j} X_{h i j}+U_{0 j}+\sum_{h=1}^{k} U_{h j} x_{h i j}
$$

Where,

$$
\pi_{i j}=\frac{\exp \left(\beta_{0 j}+U_{0 j}+\sum_{h=1}^{k} \beta_{h j} X_{h i j}+\sum_{h=1}^{k} U_{h j} X_{h i j}\right.}{1+\exp \left(\beta_{0 j}+U_{0 j}+\sum_{h=1}^{k} \beta_{h j} X_{h i j}+\sum_{h=1}^{k} U_{h j} X_{h i j}\right.}
$$

$\pi_{i j}$ represents the probability of the event for subject $i j$ who has covariate vector $X_{i j}, Y_{i j}=1$ indicates the presence (child having ARI) and $Y_{i j}=0$ the absence (child not having ARI) of the event for the given subject.

The posterior distribution is obtained by multiplying the prior distribution over all parameters by the full likelihood functions. The posterior distribution is:

$$
P\left(\beta_{h} \mid \Omega_{u}, U_{o j}, y_{i j}\right) \propto \prod_{i j} \pi_{i j}^{y_{i j}}\left(1-\pi_{i j}\right)^{1-y_{i j}} P(\beta)
$$

Where $h=1,2, \ldots \ldots \ldots \ldots \ldots$ andthe full conditional distribution of the variance-covariance parameter $\Omega_{u}$ has been given as:-

$P\left(\Omega_{u} / \beta_{h}, U_{o j}, Y_{i j}\right) \propto P\left(Y_{i j} / \beta_{h}, \Omega_{u}, U_{o j}\right) P\left(U_{o j} / \Omega_{u}\right) P\left(\Omega_{u}\right)$ 


\section{Results and Discussion}

This study was carried out to investigate the determinant factors associated with acute respiratory infections among under five years old children and overall ARI prevalence rate was $8.4 \%$, which was slightly higher than the estimated prevalence level of the country. The prevalence of ARI among males and females were $8.5 \%$ and $8.38 \%$ respectively. About $81.12 \%$ of under-five children were born to mothers who were residing in a rural area and had a higher prevalence of ARI (8.95\%) as compared to under-five children who were born to mothers who lived in urban areas (6.25\%). The major demographic and socioeconomic background characteristics of the respondents and children are presented in Table 1. The proportion of under-five children suffered from ARI varies with the household economic status. The highest incidence of ARI among under five children was found from a low income household, whereas the lowest proportion of under-five children suffered from ARI was recorded for those from higher income family.

Among 9,918 respondents, $(27.78 \%)$ of them had worked and the prevalence of ARI in under-five children whose mother had work was (9.33\%). Additionally the proportion of children who had ARI varied by educational status of mothers. The highest proportion of the children with ARI was observed for children whose mothers had no education was $(64.07 \%)$ with the prevalence of ARI were (9.60\%) as opposed to the low prevalence of the ARI among under-five children, which was recorded for children whose mothers had secondary and higher educational level was $(10.72 \%)$ with the prevalence of ARI (4.80\%).

From the major health, environmental and nutritional related background characteristics of the respondents and children the proportion of children who had ARI varied from one region to another. For example the highest prevalence of ARI was observed in Tigray $(15.31 \%)$ followed by Oromia (14.40\%) as opposed to the low prevalence which was recorded in Benishangul Gumuz (2.58\%) in two weeks preceding the survey date. Hence, there appears to be some variation in prevalence of ARI among the region of Ethiopia.

Among 9,918 under-five children, 43.10\% of them received vitamin A recently with the lowest proportion on the prevalence of ARI (7.75\%) compared to not having vitamin A recently (9\%). Additionally, $11.13 \%$ of under-five children had Diarrhea recently with the highest prevalence of ARI (24.64\%) compared to not having Diarrhea recently (6.41\%).Also the highest prevalence of ARI was observed for the child whose source of drinking water were unprotected/unimproved $(9.39 \%)$. 
Table 1: Distribution of Demographic, Socio-economic Health, Environmental and Nutritional related Factors on prevalence of ARI among under-five children in Ethiopia (EDHS, 2016).

\begin{tabular}{|c|c|c|c|c|c|}
\hline \multirow[b]{2}{*}{ Variables } & \multirow[b]{2}{*}{ Categories } & \multicolumn{2}{|c|}{ ARI STATUS } & \multirow[b]{2}{*}{ Total (\%) } & \multirow[b]{2}{*}{ P-value } \\
\hline & & $\begin{array}{l}\text { Had no ARI } \\
\text { Count }(\%)\end{array}$ & $\begin{array}{l}\text { Had ARI } \\
\text { Count (\%) }\end{array}$ & & \\
\hline Sex of child & $\begin{array}{l}\text { Male } \\
\text { Female }\end{array}$ & $\begin{array}{l}4632(91.5) \\
4449(91.62) \\
\end{array}$ & $\begin{array}{l}430(8.5) \\
407(8.38)\end{array}$ & $\begin{array}{l}5062(51.04) \\
4856(48.96) \\
\end{array}$ & 0.839 \\
\hline Child age & $\begin{array}{l}66 \text { months } \\
6-11 \text { months } \\
12-23 \text { months } \\
24-35 \text { months } \\
36-47 \text { months } \\
48-59 \text { months }\end{array}$ & $\begin{array}{l}1022(91.57) \\
891(87.70) \\
1704(88.61) \\
1748(91.71) \\
1755(92.56) \\
1961(95.14)\end{array}$ & $\begin{array}{l}94(8.43) \\
125(12.3) \\
219(11.39) \\
158(8.29) \\
141(7.44) \\
100(4.85)\end{array}$ & $\begin{array}{l}1116(11.25) \\
1016(10.24) \\
1923(19.39) \\
1906(19.22) \\
1896(19.22) \\
2061(20.78)\end{array}$ & $0.000^{*}$ \\
\hline Mothers age & $\begin{array}{l}15-19 \\
20-34 \\
35-49\end{array}$ & $\begin{array}{l}336(91.30) \\
6565(91.45) \\
2180(91.90)\end{array}$ & $\begin{array}{l}32(8.70) \\
614(8.55) \\
191(8.05)\end{array}$ & $\begin{array}{l}368(3.71) \\
7179(72.38) \\
2371(23.90)\end{array}$ & 0.740 \\
\hline Wealth index & Poorest & $3325(90.50)$ & $350(9.50)$ & $3675(37.05)$ & $0.000 *$ \\
\hline & $\begin{array}{l}\text { Poorer } \\
\text { Middle } \\
\text { Richer } \\
\text { Richest }\end{array}$ & $\begin{array}{l}1493(89.72) \\
1272(92.17) \\
1134(93.33) \\
1857(93.60)\end{array}$ & $\begin{array}{l}171(10.28) \\
108(7.83) \\
81(6.67) \\
127(6.40)\end{array}$ & $\begin{array}{l}1664(16.78) \\
1380(13.91) \\
1215(12.25) \\
1984(20.00)\end{array}$ & \\
\hline Place of residence & $\begin{array}{l}\text { Rural } \\
\text { Urban } \\
\end{array}$ & $\begin{array}{l}7325(91.05) \\
1756(93.75) \\
\end{array}$ & $\begin{array}{l}720(8.95) \\
117(6.25) \\
\end{array}$ & $\begin{array}{l}8045(81.12) \\
1873(18.88) \\
\end{array}$ & $0.000^{*}$ \\
\hline Mother education & $\begin{array}{l}\text { No education } \\
\text { Primary } \\
\text { Secondary } \\
\text { and above }\end{array}$ & $\begin{array}{l}5806(91.40) \\
2261(90.40) \\
1012(95.20) \\
\end{array}$ & $\begin{array}{l}548(9.60) \\
240(8.60) \\
49(4.8) \\
\end{array}$ & $\begin{array}{l}6354(64.07) \\
2501(25.22) \\
1063(10.72) \\
\end{array}$ & $0.000 *$ \\
\hline Mother occupation & $\begin{array}{l}\text { Not working } \\
\text { Working }\end{array}$ & $\begin{array}{l}\text { 6583(91.90) } \\
2498(90.67)\end{array}$ & $\begin{array}{l}580(8.10) \\
257(9.33)\end{array}$ & $\begin{array}{l}7163(72.22) \\
2755(27.78)\end{array}$ & $0.048^{*}$ \\
\hline $\begin{array}{l}\text { Vitamin } \\
\text { supplement }\end{array}$ & $\begin{array}{l}\text { No } \\
\text { Yes }\end{array}$ & $\begin{array}{l}5134(91.00) \\
3947(92.25)\end{array}$ & $\begin{array}{l}505(9.00) \\
332(7.75)\end{array}$ & $\begin{array}{l}5639(56.90) \\
4279(43.10)\end{array}$ & $0.034 *$ \\
\hline Breast feeding & $\begin{array}{l}\text { Never breast } \\
\text { feed } \\
\text { ever breast } \\
\text { feed not } \\
\text { currently } \\
\text { Still breast } \\
\text { feed }\end{array}$ & $\begin{array}{l}358(94.46) \\
4932(93.25) \\
3791(89.20)\end{array}$ & $\begin{array}{l}21(5.54) \\
357(6.75) \\
459(10.80)\end{array}$ & $\begin{array}{l}379(3.82) \\
5289(53.33) \\
4250(42.85)\end{array}$ & $0.000^{*}$ \\
\hline History of diarrhea & $\begin{array}{l}\text { No } \\
\text { Yes } \\
\end{array}$ & $\begin{array}{l}8249(93.59) \\
832(75.36)\end{array}$ & $\begin{array}{l}565(6.41) \\
272(24.64) \\
\end{array}$ & $\begin{array}{l}8814(88.87) \\
1104(11.13) \\
\end{array}$ & $0.000^{*}$ \\
\hline $\begin{array}{l}\text { Type of cooking } \\
\text { fuel }\end{array}$ & $\begin{array}{l}\text { Unclean/unsa } \\
\text { fe }\end{array}$ & $8599(91.40)$ & $810(8.6)$ & 9409(94.87) & $0.009^{*}$ \\
\hline
\end{tabular}




\begin{tabular}{|l|l|l|l|l|l|} 
& Clean/Safe & $482(94.70)$ & $27(5.30)$ & $509(5.13)$ & \\
\hline Wasting & Not wasted & $8058(91.80)$ & $723(8.20)$ & $8781(88.50)$ & $0.041^{*}$ \\
& Wasted & $1023(89.97)$ & $114(10.03)$ & $1137(11.50)$ & \\
\hline Stunting & Not stunted & $5880(92.77)$ & $458(7.23)$ & $6338(63.90)$ & $0.000^{*}$ \\
& Stunted & $3201(89.41)$ & $379(10.59)$ & $3580(36.10)$ & \\
\hline $\begin{array}{l}\text { Number of } \\
\text { child }\end{array}$ & $1-3$ child & $4551(92.00)$ & $397(8.00)$ & $4948(49.89)$ & 0.309 \\
& $4-6$ child & $3226(91.05)$ & $317(8.95)$ & $3543(35.72)$ & \\
& above 6 child & $1304(91.40)$ & $123(8.60)$ & $1427(14.39)$ & \\
\hline Source of water & Unprotected & $5182(90.61)$ & $537(9.39)$ & $5719(57.66)$ & $0.002^{*}$ \\
& Protected & $3899(92.85)$ & $300(7.15)$ & $4199(42.34)$ & \\
\hline Region & Tigray & $835(84.69)$ & $151(15.31)$ & $986(9.94)$ & $0.000^{*}$ \\
\hline & Affar & $892(92.44)$ & $73(7.56)$ & $965(9.73)$ & \\
\hline & Amhara & $824(89.18)$ & $100(10.82)$ & $924(9.32)$ & \\
\hline & Oromia & $1272(85.60)$ & $214(14.40)$ & $1486(14.98)$ & \\
\hline & Somale & $1329(95.68)$ & $60(4.32)$ & $1389(14.00)$ & \\
\hline & Benishangul & $793(97.42)$ & $21(2.58)$ & $814(8.21)$ & \\
& gumuz & & & & \\
\hline & SNNPS & $1081(90.31)$ & $116(9.69)$ & $1197(12.07)$ & \\
\hline & Gambela & $624(95.41)$ & $30(4.59)$ & $654(6.59)$ & \\
\hline & Harari & $543(97.31)$ & $15(2.69)$ & $558(5.63)$ & \\
\hline & Addis Ababa & $411(94.05)$ & $26(5.95)$ & $437(4.41)$ & \\
\hline & Dire Dawa & $477(93.90)$ & $31(6.10)$ & $508(5.12)$ & \\
\hline & & & & & \\
& & & & & \\
\hline & & & & & \\
& & & & & \\
\hline & & &
\end{tabular}

*significant

\subsection{Bayesian Multilevel Logistic Regression Analysis}

The Bayesian method gives estimates of parameters by sampling them from their posterior distributions through an MCMC method. The metropolis hasting algorithm were implemented using non-informative uniform prior distribution with scale parameter $(0,1)$ for the fixed effects and inverse gamma distribution with a scale of 0.001 and shape 0.001 for random effect [23]. In Bayesian multilevel models, three models were fitted. Model 1 does not include any covariate; Model 2 includes fixed effects and regional random effects; and Model 3 includes variables in Model 2 and variable that has a significant impact on ARI among under five children in the Bayesian multilevel intercept model by observing their respective region effect to identify the appropriate model which fits our data. For each model, 85,000 MCMC iterations were run, with the initial 15,000 burn-in terms discarded, and thereafter keeping every 20th sample value to make observations independent or low autocorrelations. The 60,000 iterations left were used to assess convergence of the chain and parameter estimation.

\subsection{Model comparison of Bayesian Multilevel logistic}

\section{regressions}


From Table 2 we see that the comparison of the fit of Bayesian multilevel logistic regression models using the summary of the fitted model. The model, which has small DIC, is the best model for the data set, so the result, shows that Bayesian multilevel random coefficient model was an improved fit as compared to the rest models in any combination of variables in the data set.

Table 2: DIC values for model comparisons

\begin{tabular}{|l|c|c|c|c|}
\hline \multicolumn{1}{|c|}{ Model } & $\overline{\boldsymbol{D}}$ & $\boldsymbol{D}(\overline{\boldsymbol{\theta}})$ & $\boldsymbol{P d}$ & DIC \\
\hline Empty model & 5097.64 & 4848.33 & 249.31 & 5346.95 \\
\hline Random intercept model & 4699.42 & 4427.04 & 272.38 & 4971.79 \\
\hline Random coefficient model & 4612.55 & 4275.15 & 337.40 & 4949.95 \\
\hline
\end{tabular}

\subsection{Result of Bayesian Multilevel Empty Model}

From Table 3, the overall posterior mean of ARI status of under five children without incorporating the covariate is estimated to be $\beta_{0 j}=-2.789$ and the between-region (level two) variance of ARI status of under five children is estimated as $\delta_{u o}^{2}=0.998 \mathrm{which}$ is found to be significant because the credible interval of the respective parameters was greater than zero.

Here the null hypothesis tested is $\sigma_{0 u}^{2}=0$. i.e., there is no regional variation in the incidence of ARI among under five children in Ethiopia. Based on the above result, the values are significant at $95 \%$ credible interval, which means that the interval is greater than zero, therefore, the null hypothesis had been rejected indicating strong evidence that the between region variance is greater than zero.

In order to get an idea of how much of the variation in ARI status of among under five children was attributable to the region level factors, it is useful to see the intra-region correlation coefficient (ICC) as $\hat{\rho}=\frac{0.998}{0.998+3.29}=0.233$, which measures the proportion of variance of the ARI of under five children that is between regions, not within regions. This means that around $23.3 \%$ of the variance in ARI of under five children are due to variation between regions. Whereas the remaining $76.7 \%$ attributable to individual level, i.e., within regional differences.

Table 3: Posterior summaries for parameters of the empty model 


\begin{tabular}{|l|l|l|l|l|l|l|}
\hline Model & Post. Mean & MC error & SD & $2.5 \%$ & $50 \%$ & $97.5 \%$ \\
\hline Fixed intercept $\left(\beta_{0 j}\right)$ & -2.789 & 0.0003 & 0.072 & -2.936 & -2.789 & -2.652 \\
\hline Random intercept $\operatorname{var}\left(U_{0 j}\right)$ & 0.998 & 0.0006 & 0.136 & 0.750 & 0.989 & 1.279 \\
\hline
\end{tabular}

\subsection{Result of Random Intercept Bayesian Multilevel Model}

The overall posterior mean of ARI status is estimated to be-3.280which decreased by 0.491 as compared to an empty model (Table: 3). Therefore, indicating many variables that are included in this model have impacts on the incidence of ARIs.

The result of intercept model displayed in (Table 4) also estimates that, the variance of random effect at the regional level var $\left(u_{0 j}\right)=1.107$ since the $95 \%$ credible interval was greater than zero under the interval, which indicates that there is a significant regional variation.

The results displayed in (Table:4) showed that the intra-region correlations coefficient (ICC) is estimated as $\hat{\rho}=\frac{1.107}{1.107+3.29}=0.252$. This means that about $25.2 \%$ of the total variability in ARI status of under-five children is due to difference across regions, with the remaining unexplained $74.8 \%$ attributable to individual differences.

Table 4: Bayesian Multilevel Logistic Regression of Random Intercept

\begin{tabular}{|l|l|l|l|l|l|l|l|}
\hline \multicolumn{9}{|c|}{ Fixed effect } \\
\hline Variables & Category & $\begin{array}{l}\text { Coefficie } \\
\text { nt }\end{array}$ & SD & MC error & $2.5 \%$ & $50 \%$ & $97.5 \%$ \\
\hline- & Intercept & -3.280 & 0.367 & 0.0063 & -4.035 & -3.270 & -2.563 \\
\hline Sex & Male(ref) & & & & & & \\
& Female & 0.007 & 0.080 & 0.0003 & -0.151 & 0.008 & 0.170 \\
\hline Child age & <6 (ref) & & & & & & \\
& $6-11$ & 0.245 & 0.162 & 0.0007 & -0.066 & 0.243 & 0.563 \\
& $12-23$ & 0.087 & 0.147 & 0.0007 & -0.195 & 0.088 & 0.369 \\
& $24-35$ & -0.177 & 0.169 & 0.0009 & -0.509 & -0.180 & 0.153 \\
& $36-47$ & -0.193 & 0.186 & 0.001 & -0.556 & -0.193 & 0.176 \\
& $48-59$ & -0.539 & 0.196 & 0.001 & -0.925 & -0.539 & -0.148 \\
\hline Maternal age & $15-19($ ref) & & & & & & \\
& $20-34$ & 0.153 & 0.223 & 0.0022 & -0.264 & 0.146 & 0.626 \\
& $35-49$ & 0.050 & 0.249 & 0.0021 & -0.419 & 0.043 & 0.556 \\
\hline Wealth index & & & & & & & \\
of household & Poorest (ref) & & & & & & \\
& Poorer & -0.214 & 0.124 & 0.0005 & -0.459 & -0.214 & 0.024 \\
& Middle & -0.609 & 0.145 & 0.0005 & -0.892 & -0.609 & -0.331 \\
& Richer & -0.812 & 0.161 & 0.0006 & -1.130 & -0.813 & -0.509 \\
& Richest & -0.598 & 0.204 & 0.0009 & -0.994 & -0.595 & -0.213 \\
\hline Place of & Rural (ref) & & & & & & \\
residence & & & & & & &
\end{tabular}




\begin{tabular}{|c|c|c|c|c|c|c|c|}
\hline & Urban & 0.244 & 0.220 & 0.001 & -0.194 & 0.245 & 0.684 \\
\hline Breast feeding & $\begin{array}{l}\text { Never breast } \\
\text { feed(ref) } \\
\text { Ever breast } \\
\text { feed, not } \\
\text { currently } \\
\text { Still breast } \\
\text { feed }\end{array}$ & $\begin{array}{l}0.229 \\
0.356\end{array}$ & $\begin{array}{l}0.253 \\
0.258\end{array}$ & $\begin{array}{l}0.0025 \\
0.0028\end{array}$ & $\begin{array}{l}-0.249 \\
-0.150\end{array}$ & $\begin{array}{l}0.219 \\
0.349\end{array}$ & $\begin{array}{l}0.737 \\
0.868\end{array}$ \\
\hline $\begin{array}{l}\text { Maternal } \\
\text { Education }\end{array}$ & $\begin{array}{l}\text { No } \\
\text { education(re } \\
\text { f) } \\
\text { Primary } \\
\text { Secondary } \\
\text { and higher }\end{array}$ & $\begin{array}{l}0.154 \\
-0.449\end{array}$ & $\begin{array}{l}0.105 \\
0.201\end{array}$ & $\begin{array}{l}0.0004 \\
0.0007\end{array}$ & $\begin{array}{l}-0.051 \\
-0.851\end{array}$ & $\begin{array}{l}0.154 \\
-0.443 \\
\end{array}$ & $\begin{array}{l}0.362 \\
-0.065\end{array}$ \\
\hline $\begin{array}{ll}\text { Vitamin } & \text { A } \\
\text { Supplement } & \end{array}$ & $\begin{array}{l}\text { No (ref) } \\
\text { Yes }\end{array}$ & -0.183 & 0.088 & 0.0003 & -0.355 & -0.184 & -0.010 \\
\hline $\begin{array}{l}\text { Had diarrhea } \\
\text { Recently }\end{array}$ & $\begin{array}{l}\text { No(ref) } \\
\text { Yes }\end{array}$ & 1.435 & 0.096 & 0.0003 & 1.245 & 1.590 & 1.621 \\
\hline Fuel type & $\begin{array}{l}\text { Unclean/uns } \\
\text { afe(ref) } \\
\text { Safe/clean }\end{array}$ & -0.065 & 0.266 & 0.0009 & -0.587 & -0.061 & 0.454 \\
\hline $\begin{array}{l}\text { Maternal } \\
\text { Work }\end{array}$ & $\begin{array}{l}\text { Not } \\
\text { working(ref) } \\
\text { Working }\end{array}$ & 0.268 & 0.094 & 0.0003 & 0.084 & 0.268 & 0.459 \\
\hline Wasting & $\begin{array}{l}\text { No(ref) } \\
\text { Yes }\end{array}$ & 0.122 & 0.120 & 0.0004 & -0.116 & 0.119 & 0.354 \\
\hline Stunting & $\begin{array}{l}\text { No(ref) } \\
\text { Yes }\end{array}$ & 0.456 & 0.087 & 0.0003 & 0.292 & 0.456 & 0.632 \\
\hline $\begin{array}{l}\text { Number of } \\
\text { living child }\end{array}$ & $\begin{array}{l}1-3 \text { (ref) } \\
4-6 \\
\text { Above } 6\end{array}$ & $\begin{array}{l}0.126 \\
0.212 \\
\end{array}$ & $\begin{array}{l}0.100 \\
0.150 \\
\end{array}$ & $\begin{array}{l}0.0004 \\
0.0006 \\
\end{array}$ & $\begin{array}{l}-0.070 \\
-0.088 \\
\end{array}$ & $\begin{array}{l}0.123 \\
0.213 \\
\end{array}$ & $\begin{array}{l}0.319 \\
0.499 \\
\end{array}$ \\
\hline $\begin{array}{l}\text { Source of } \\
\text { drinking water }\end{array}$ & $\begin{array}{l}\text { Unprotected } \\
\text { (ref) } \\
\text { Protected }\end{array}$ & -0.203 & 0.095 & 0.0003 & -0.387 & -0.202 & -0.016 \\
\hline \multicolumn{8}{|c|}{ Random effect } \\
\hline $\operatorname{Var}\left(u_{0 j}\right)=$ & & 1.107 & 0.158 & 0.0007 & 0.829 & 1.095 & 1.456 \\
\hline
\end{tabular}

\subsection{Result of Random Coefficient Bayesian Multilevel Model}

The results of Multilevel random coefficient model was revealed that, age of child, wealth index of household, maternal education level, vitamin A supplement, had diarrhea recently, maternal working status, stunting and source of drinking water, were found to be significant, indicating strong effects on ARIs of under five children and also contributing to variations among regional state in Ethiopia. 
The odds of incidence of ARI among under five children in the age group of 48-59 month, were $40.2 \%(\mathrm{OR}=0.598,95 \%$ Credible interval: $(-0.908,-0.130))$ times less likely having ARI to those children in the age group less than 6 months.

The odds of under-five children developing ARI among mothers who completed secondary and above educational levels to have ARI was $33.5 \%(\mathrm{OR}=0.635$, credible interval $(-0.875$, 0.067)) times less likely than under five children affected by ARIs as compared with children whose mothers' had no education.

According to this study Vitamin A consumption of children in the last six months was found that, it had a significant effect in the ARIs. The odds of a child who had received vitamin A recently was $16.6 \%(\mathrm{OR}=0.834$, credible interval $(-0.359,-0.011))$ less likely to suffer in ARI compared to a child not received vitamin A recently. Indeed, the odds of Under-five child who had Diarrhea recently were $4.284(\mathrm{OR}=4.284$, credible interval $:(1.260,1.649))$ times more likely a child who have ARI than who had not Diarrhea recently.

Maternal occupation also has a statistically significant association with ARI; accordingly, the odds of children whose mothers had occupation, to have ARI incidence was increased by $30.9 \%$ ( OR: 1.309 , CI $(0.011,0.540))$ compared to mothers had no occupations. Another finding from the Table 5 showed that, chronic nutrition status of children explained by stunting was included in the model and it has a significant effect on ARI. The odds of underfive children who were stunted were $59.5 \%(\mathrm{OR}=1.595$, credible interval $(0.291,0.640))$ times more likely to experience ARI than who were not stunted.

This study also revealed that, the source of drinking water has a significant effect on ARI. The odds of children using protected source of drinking water were $18.6 \%(\mathrm{OR}=0.814$, credible interval :( $-0.40,-0.016))$ less likely than having ARI as compared with a child using unprotected source of drinking water.

Table 5 below, also estimates the variance of random effect at the regional level, $\operatorname{var}\left(u_{0 j}\right)$. Thus, the value of $\operatorname{Var}\left(u_{0 j}\right)=1.295$ indicate there was significant variation (which means the 95\% credible intervals is greater than zero). This confirmed the significance of the regional difference in incidence of ARIs in the regional state of Ethiopia. The researcher tried to identify to see the level of variation; that the intra-region correlation coefficient ICC is estimated as $\hat{\rho}=\frac{1.295}{1.295+3.29}=0.282$. This means that about $28.2 \%$ of the total variability in 
incidence of ARI are due to differences across regions, with the remaining unexplained $71.8 \%$ attributable to individual differences.

In this model, researcher has tested the variable that has significant impact on occurrence of ARI among under five children in the intercept model by observing their respective region effect. Consequently, regional level variables that are supposed to varying regionally such as wealth index of household and maternal working status have been examined.

The researcher revealed that the variance of the wealth index of richer category has slopes ( $\left.\sigma_{u 11}^{2}=0.725\right)$ with a credible interval of $(95 \% \mathrm{CI}: 0.223,1.606)$ and the variance of the mothers currently working slopes $\left(\sigma_{u 21}^{2}=0.502\right)$ with $(95 \%$ CI: $0.188,1.031)$ the interval was greater than zero. This indicates that the random slope of wealth index of household and the maternal working status for incidence of ARI among under five children varies from region to region.

Table 5: Bayesian Multilevel Logistic Regression of Random Coefficient

\begin{tabular}{|c|c|c|c|c|c|c|c|c|}
\hline \multicolumn{9}{|c|}{ Fixed effects } \\
\hline Variables & Category & Coefficient & MC error & SD & $\operatorname{Exp}(\beta)$ & $2.5 \%$ & $50 \%$ & $97.5 \%$ \\
\hline- & Intercept & -3.305 & 0.0057 & 0.353 & 0.0367 & -4.025 & -3.307 & -2.615 \\
\hline Sex & $\begin{array}{l}\text { Male(ref) } \\
\text { Female }\end{array}$ & 0.011 & 0.0003 & 0.081 & 1.011 & -0.143 & 0.012 & 0.169 \\
\hline $\begin{array}{l}\text { Child age in } \\
\text { months }\end{array}$ & $\begin{array}{l}<6 \text { (ref) } \\
6-11 \\
12-23 \\
24-35 \\
36-47 \\
48-59 \\
\end{array}$ & $\begin{array}{l}0.259 \\
0.095 \\
-0.155 \\
-0.164 \\
-0.514 \\
\end{array}$ & $\begin{array}{l}0.0008 \\
0.0008 \\
0.001 \\
0.0011 \\
0.0011 \\
\end{array}$ & $\begin{array}{l}0.163 \\
0.151 \\
0.175 \\
0.190 \\
0.201\end{array}$ & $\begin{array}{l}1.295 \\
1.099 \\
0.856 \\
0.849 \\
0.598\end{array}$ & $\begin{array}{l}-0.061 \\
-0.199 \\
-0.489 \\
-0.541 \\
-0.908 \\
\end{array}$ & $\begin{array}{l}0.263 \\
0.094 \\
-0.157 \\
-0.159 \\
-0.517 \\
\end{array}$ & $\begin{array}{l}0.579 \\
0.388 \\
0.188 \\
0.192 \\
-0.130 \\
\end{array}$ \\
\hline Maternal age & $\begin{array}{l}15-19 \text { (ref) } \\
20-34 \\
35-49\end{array}$ & $\begin{array}{l}0.142 \\
0.029\end{array}$ & $\begin{array}{l}0.0023 \\
0.002 \\
\end{array}$ & $\begin{array}{l}0.221 \\
0.251 \\
\end{array}$ & $\begin{array}{l}1.153 \\
1.029 \\
\end{array}$ & $\begin{array}{l}-0.282 \\
-0.462 \\
\end{array}$ & $\begin{array}{l}0.139 \\
0.024\end{array}$ & $\begin{array}{l}0.583 \\
0.532 \\
\end{array}$ \\
\hline $\begin{array}{l}\text { Wealth index } \\
\text { of household }\end{array}$ & $\begin{array}{l}\text { Poorest (ref) } \\
\text { Poorer } \\
\text { Middle } \\
\text { Richer } \\
\text { Richest } \\
\end{array}$ & $\begin{array}{l}-0.222 \\
-0.632 \\
-0.877 \\
-0.638 \\
\end{array}$ & $\begin{array}{l}0.0005 \\
0.0006 \\
0.0015 \\
0.001 \\
\end{array}$ & $\begin{array}{l}0.125 \\
0.147 \\
0.245 \\
0.210 \\
\end{array}$ & $\begin{array}{l}0.800 \\
0.532 \\
0.416 \\
0.528 \\
\end{array}$ & $\begin{array}{l}-0.472 \\
-0.927 \\
-1.417 \\
-1.051 \\
\end{array}$ & $\begin{array}{l}-0.224 \\
-0.629 \\
-0.863 \\
-0.635 \\
\end{array}$ & $\begin{array}{l}0.021 \\
-0.343 \\
-0.435 \\
-0.226 \\
\end{array}$ \\
\hline $\begin{array}{ll}\text { Place } & \text { of } \\
\text { residence }\end{array}$ & $\begin{array}{l}\text { Rural (ref) } \\
\text { Urban }\end{array}$ & 0.264 & 0.0011 & 0.225 & 1.302 & -0.174 & 0.262 & 0.709 \\
\hline $\begin{array}{l}\text { Breast } \\
\text { feeding }\end{array}$ & $\begin{array}{l}\text { Never breast } \\
\text { feed(ref) } \\
\text { Ever breast } \\
\text { feed, not } \\
\text { currently } \\
\text { Still breast } \\
\text { feed }\end{array}$ & 0.188 & 0.0024 & 0.258 & 1.207 & $\begin{array}{l}-0.273 \\
-0.158\end{array}$ & 0.333 & 0.870 \\
\hline
\end{tabular}




\begin{tabular}{|c|c|c|c|c|c|c|c|c|}
\hline $\begin{array}{l}\text { Maternal } \\
\text { education }\end{array}$ & $\begin{array}{l}\text { No } \\
\text { education(re } \\
\text { f) } \\
\text { Primary } \\
\text { Secondary } \\
\text { and higher }\end{array}$ & $\begin{array}{l}0.140 \\
-0.454\end{array}$ & $\begin{array}{l}0.0004 \\
0.0007\end{array}$ & $\begin{array}{l}0.106 \\
0.205\end{array}$ & $\begin{array}{l}1.150 \\
0.635\end{array}$ & $\begin{array}{l}-0.064 \\
-0.875\end{array}$ & $\begin{array}{l}0.140 \\
-0.459 \\
\end{array}$ & $\begin{array}{l}0.350 \\
-0.067\end{array}$ \\
\hline $\begin{array}{l}\text { Vitamin A } \\
\text { supplement }\end{array}$ & $\begin{array}{l}\text { No (ref) } \\
\text { Yes }\end{array}$ & -0.182 & 0.0003 & 0.088 & 0.834 & -0.359 & -0.183 & -0.011 \\
\hline $\begin{array}{l}\text { Had diarrhea } \\
\text { recently }\end{array}$ & $\begin{array}{l}\text { No(ref) } \\
\text { Yes }\end{array}$ & 1.455 & 0.0003 & 0.099 & 4.284 & 1.260 & 1.455 & 1.649 \\
\hline Fuel type & $\begin{array}{l}\text { Unclean/uns } \\
\text { afe(ref) } \\
\text { Safe/clean }\end{array}$ & -0.062 & 0.001 & 0.269 & 0.939 & -0.607 & -0.051 & 0.445 \\
\hline $\begin{array}{l}\text { Maternal } \\
\text { work }\end{array}$ & $\begin{array}{l}\text { Not } \\
\text { working(ref) } \\
\text { Working }\end{array}$ & 0.270 & 0.0007 & 0.137 & 1.309 & 0.011 & 0.271 & 0.540 \\
\hline Wasting & $\begin{array}{l}\text { No(ref) } \\
\text { Yes }\end{array}$ & 0.125 & 0.0004 & 0.122 & 1.133 & -0.117 & 0.125 & 0.360 \\
\hline Stunting & $\begin{array}{l}\text { No(ref) } \\
\text { Yes }\end{array}$ & 0.467 & 0.0003 & 0.089 & 1.595 & 0.291 & 0.464 & 0.640 \\
\hline $\begin{array}{l}\text { Number of } \\
\text { living child }\end{array}$ & $\begin{array}{l}1-3 \text { (ref) } \\
4-6 \\
\text { Above } 6\end{array}$ & $\begin{array}{l}0.126 \\
0.217\end{array}$ & $\begin{array}{l}0.0004 \\
0.0006\end{array}$ & $\begin{array}{l}0.101 \\
0.152\end{array}$ & $\begin{array}{l}1.134 \\
1.242\end{array}$ & $\begin{array}{l}-0.068 \\
-0.072\end{array}$ & $\begin{array}{l}0.121 \\
0.215\end{array}$ & $\begin{array}{l}0.328 \\
0.515\end{array}$ \\
\hline $\begin{array}{ll}\begin{array}{l}\text { Source } \\
\text { drinking }\end{array} & \text { of } \\
\text { water } & \end{array}$ & $\begin{array}{l}\text { Unprotected } \\
\text { (ref) } \\
\text { Protected }\end{array}$ & -0.206 & 0.0004 & 0.098 & 0.814 & -0.400 & -0.204 & -0.016 \\
\hline$\sigma_{u 0}^{2}$ & Random & $\frac{\text { effect }}{1.295}$ & 0.0012 & 0.203 & & 0.925 & 1.284 & 1.724 \\
\hline$\sigma_{u 11}^{2}$ & Random & $\begin{array}{l}\text { slope } \\
0.725\end{array}$ & 0.0049 & 0.351 & & 0.223 & 0.666 & 1.606 \\
\hline$\sigma_{u 21}^{2}$ & & 0.502 & 0.0032 & 0.223 & & 0.188 & 0.468 & 1.031 \\
\hline
\end{tabular}

\subsection{Model Diagnostic Check}

After the model is developed, model effectiveness is checked by goodness of fit and by monitoring the convergence. Diagnostic is conducted by calculating quintiles (the 2.5 and 97.5\% quintiles) that will form a central interval estimate. Furthermore, for each of the posterior distributions of the parameter in the model diagnostics, the trace of the chains, autocorrelations (AC) and partial autocorrelations (PAC) functions at iteration $t$ and t-k having accounted for iterations $-1, \ldots, \mathrm{t}-(\mathrm{k}-1)$, and the Monte Carlo standard errors (MCSE) are investigated. 
The convergence of posterior estimate has been checked using an effective sample size estimates that are greater than 200. To obtain efficient posterior estimate we save more samples and posterior estimates become more accurate. This has been presented in different plots for different variables. The plots of convergence for wealth index and diarrhea are present in Figure 1 and 2 as an example.

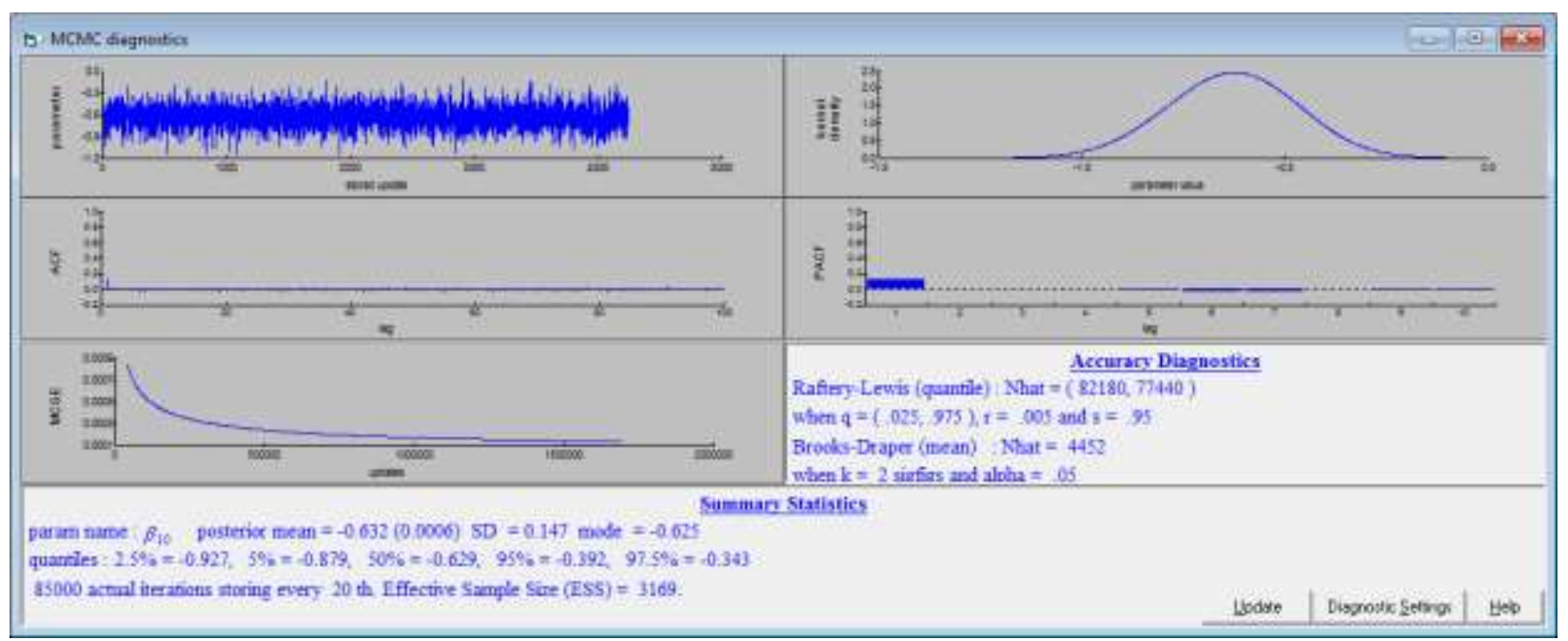

Figure 1: Plots of wealth index of household in middle class

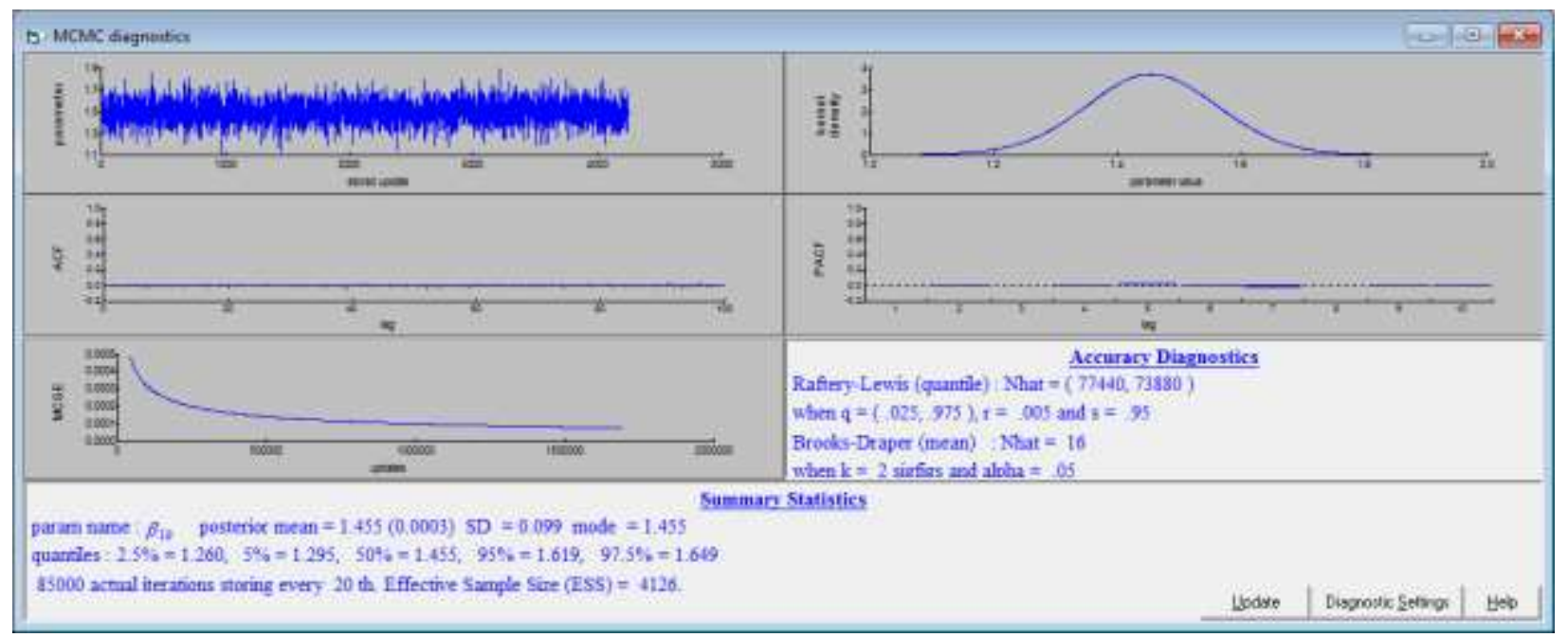

Figure 2: Plots of a child had diarrhea recently

Since the traces plots, AC and PAC functions are less correlated and the MCSE be close to zero we expected our model is good enough to fit our data. A detail method for parameter estimation and model diagnostics using MCMC simulations methods can be found from MLwiN manual [24]. For all our variables, the MC error for each significant variable is less than $5 \%$ times its standard deviation. The convergence and accuracy of posterior estimates are attained and the model is appropriate enough to estimate the posterior statistics. 


\subsection{Discussion}

This study was intended to identify factors associated with the prevalence of ARI among under-five children. The Bayesian random coefficient model found better in fitting the data appropriately based upon their DIC. The analysis revealed that, age group of children between 48-59 months has lower odds of ARIs as compared with children less than 6 months, this means that as age of child increase the occurrence of ARI. This result was confirmed by similar investigations studies done in Ahmadabad City[18]. This is because as a child gets older, their immunity grows stronger and becomes better able to resist infection like respiratory infections.

Mother's educational status was strongly associated with ARIs. The result show that mothers that are more educated become less fatalistic about their children's' illnesses, they are more capable of seeking available health facilities and their greatly change the traditional balance of family relationships with profound effects on childcare. This means, caregivers with high educational level were more likely to seek appropriate care for their child that is consistent with past literatures $[25,26,27$, and [28].

The working status of a mother is one of an important determinant of incidence of ARI among children under the age of five years in Ethiopia. Based on the working status, children with a mother working have lower ARI than those who are not working. Our study's' findings is in line with Jabessa and others literatures [26, 29].

Household wealth index is also a significant factor with incidence of ARI. A higher wealth index reduces the probability of ARI occurrence compared with lower index. This finding is also in line with studies done in Uganda that the probability of occurrence of ARI reduced by $5 \%-18 \%$ which confirmed with [30]. It is known that families with high socioeconomic status are supposed to drink more piped water, and use hygienic toilets in low-income countries.

A child with diarrhea had $28.4 \%$ times more likely to have low ARI than not. This shows diarrhea affect conversely ARI for children under the age of five years [31]. Children who were chronically malnourished were $59.5 \%$ more likely to experience high ARI than those children under the age of five years who were not malnourished. The possible reason might me due to malnutrition impairs the function of the immune system and can lead to increase the severity, duration of and susceptibility to acute respiratory infection or due to lower 
intake of adequate food, improper treatment and insufficient care giving a child may exposed to higher ARIs $[18,30]$.

A child who had received vitamin A recently was 16.6 percent less likely to suffer in ARI compared to a child not receiving vitamin A recently. Promoting Vitamin A supplementation for all children may enhance the health status of children. Different studies confirmed our finding $[32,33]$. Drinking water was one of the other important determinants for incidence of ARIs. The odds of children using protected source of drinking water were 18.6 percent less likely than those who are using unprotected source of drinking water. Literatures on source of drinking water suggest that the main causes of diarrhea are source of drinking water $[34,35]$.

\section{Conclusions}

This study found that demographic, socioeconomic, health, nutritional and environmental variables considered in this study have significant influence on the ARI morbidity among under-five children. We demonstrated that children born in lower socioeconomic groups suffered more from ARI than children born in higher socioeconomic groups and a child who had diarrhea was more suffered from ARI. It also revealed that prevalence of ARI among under-five children was less likely for children whose mothers are from secondary and above educational level as compared to those of the uneducated and the risk of ARI decreases as the age of the child increases. Vitamin A supplement is also another significantly associated with the incidence of ARI among under five children. The probability of child suffered from ARI was less for children who had vitamin A as compared to those who do not received Vitamin A. The odds of children using an improved source of drinking water were less likely to suffer from ARI compared to those who do not use improved source. Likewise, the odds of children having mothers who had occupation experienced lower ARI as compared to mothers who had no occupation. Stunted children also had more likely to have ARI than who do not.

The effect of regional variations in the wealth index of household and maternal working status further implies the existence of considerable difference in prevalence of ARI among regions and a model with a random coefficient is more appropriate to explain the regional variation than a model with empty and intercept model.

There has been a considerable difference among regions through children ARI prevalence rate in Ethiopia. Change in lifestyle, culture and environmental factors may compensate the 
regional disparities in Ethiopia. The prevalence of ARI exhibits a significant variation among regions in Ethiopia.

\section{Declarations}

\section{Ethics Approval and Consent to Participate}

All participants and parents/legal guardian of minors and illiterate respondents gave written informed consent for the participation during the survey. The ethics committee and research advisory board of Central Statistical Agency has approved this consent. Further Jimma University research and ethics committee approved the research protocol. All procedures performed in this study involving human participants were in accordance with the ethical standards of the institutional and national research committee.

\section{Consent for Publication}

Not applicable

\section{Availability of Data and Materials}

The datasets generated and analyzed during the present study are available from the corresponding author on reasonable request.

\section{Competing interests}

The authors declare that they have no competing interests.

\section{Funding}

Not applicable

\section{Authors' Contributions}


This work was carried out in collaboration between all authors. AM and TA conceived the idea of the paper. AM analyzed the data and wrote the first draft of the paper. AM, TA and MS revised further to improve the paper. All authors read and approved the final manuscript.

\section{Acknowledgements}

The authors would like to thank Central Statistical Agency for permitting us to use the data analyzed in this study. Our special appreciation goes to Mizan Tepi and Jimma Universities for the financial supports for this study.

\section{Authors' Information}

Amanuel Merera, M.Sc

Mizan-Tepi University, Department of statistics, Mizan-Tepi, Ethiopia

Tilahun Asena, PhD

Arba Minch University, Department of Statistics, 21, Arba Minch, Ethiopia

Mebratu Senbeta, PhD

Arba Minch University, Department of Economics, 21, Arba Minch, Ethiopia

Corresponding author: Tilahun Asena

\section{Abbreviations}

ARI Acute Respiratory Infection

AIC/BIC Akaike/Bayesian Information Criteria

CSA Central Statistics Agency of Ethiopia

DIC Deviance Information Criterion

EA Enumeration Areas

EDHS Ethiopian Demographic Health Survey

ICC Intra class Correlation Coefficient

MCMC Markov Chain Monte Carlo 


\section{References}

[1] UNICEF (2015). Committing to Child Survival: A Promise Renewed - Progress Report 2014. UNICEF.www.unicef.org.

[2] Mortal, G. B. D. (2015). Global, regional, and national age-sex specific all-cause and cause-specific mortality for 240 causes of death, 1990-2013: a systematic analysis for the Global Burden of Disease Study 2013. Lancet, 385(9963), 117-171.

[3] Williams BG, Gouws E, Boschi PC, Bryce J, Dye C (2002) Estimates of Worldwide distribution of child death from acute respiratory infections. Lancet infec Dis 2(1): 25-32.

[4] Montasser, N., Helal, R., \& Rezq, R. (2012). Assessment and classification of acute respiratory tract infections among Egyptian rural children. British Journal of Medicine and Medical Research, 2(2), 216.

[5] Liu L, Johnson HL, Cousens S, Perin J, Scott S, et al. (2012). Global, regional, and national causes of child mortality: An updated systematic analysis for 2010 with time trends since 2000. Lancet 379: 2151-61

[6] Nair, H., Simões, E. A., Rudan, I., Gessner, B. D., Azziz-Baumgartner, E., Zhang, J. S. F., \& Baggett, H. C. (2013). Global and regional burden of hospital admissions for severe acute lower respiratory infections in young children in 2010: a systematic analysis. The Lancet, 381(9875), 1380-1390.

[7] Sonego, M., Pellegrin, M. C., Becker, G., \& Lazzerini, M. (2015). Risk factors for mortality from acute lower respiratory infections (ALRI) in children under five years of age in low and middle-income countries: a systematic review and meta-analysis of observational studies. PloS one, 10(1), e0116380.

[8] UNICEF. (2016). A Fair Chance for Every Child: The State of the World's Children 2016.

[9] Chatterjee, S. (2016). A study of epidemiological factors related to acute respiratory infection in under five children attending the immunization clinic of Calcutta National Medical College and Hospital. Internet J Pulm Med, 7(2), 1-6.

[10] Federal Democratic Republic of Ethiopia Ministry of Health. Health Sector Transformation Plan, August 2015.PAGE 24.

[11] A Survey of the last ten kilometers project (L10K), (2013). Integrated Community Case Management (iCCM) Survey in Amhara, SNNP and Tigray regions.

[12] CSA, I. (2016). Central statistical agency (CSA) [Ethiopia] and ICF. Ethiopia demographic and health survey, Addis Ababa, Ethiopia and Calverton, Maryland, USA.

[13] Acquah, H. D. (2013). Bayesian logistic regression modelling via markov chain Monte Carlo algorithm. Journal of Social and Development Sciences, 4(4), 193-197. 
[14] Kawo, K. N., Asfaw, Z. G., \& Yohannes, N. (2018). Multilevel Analysis of Determinants of Anemia Prevalence among Children Aged 6-59 Months in Ethiopia: Classical and Bayesian Approaches. Anemia, 2018.

[15] Gelman, A., B., C. J., Stern, H. S., Dunson, D. B., Vehtari, A., \& Rubin, D. (2014). Bayesiandata analysis. New York, NY, USA: Chapman \& Hall.

[16] Gelman A., Carlin J.B., Stern H.S., Rubin D.B. (2000). Bayesian data analysis, Chapman \& Hall/CRC, USA.

[17] Ibrahim J.G., Chen M.H. (2000). Power Prior Distributions for Regression Models, Statistical Science, 15 (1), 46-60.

[18] Geberetsadik, A., Worku, A., \& Berhane, Y. (2015). Factors associated with acute respiratory infection in children under the age of 5 years: evidence from the 2011 Ethiopia Demographic and Health Survey. Pediatric health, medicine and therapeutics, 6, 9.

[19] Harerimana, J. M., Nyirazinyoye, L., Thomson, D. R., \& Ntaganira, J. (2016). Social, economic and environmental risk factors for acute lower respiratory infections among children under five years of age in Rwanda. Archives of Public Health, 74(1), 19.

[20] Snijders T.A.B., and Bosker, R.(1999). Multilevel Analysis. Sage, Thousand Oaks. CA

[21]Goldstein, H. (2003). Multilevel Statistical Models. Arnold, London.

[22] Rasbash J, Charlton C, Browne WJ, et al. (2012). MLwiN Version 2.26, Centre for Multilevel Modelling, University of Bristol.

[23] Browne WJ, Charlton C, Rasbash J, Kelly M, Pillinger R (2016) MCMC estimation in MLwiN version 2.36. Centre for mutlilevel modelling. University of Bristol, Bristol

[24] Browne, W. J., \& Rasbash, J. (2009). MCMC estimation in MLwiN. Bristol: Centre of Multilevel Modelling, University of Bristol.

[25] Rehman, A., Shaikh, B. T., \& Ronis, K. A. (2014). Health care seeking patterns and out of pocket payments for children under five years of age living in Katchi Abadis (slums), in Islamabad, Pakistan. International Journal for Equity in Health, 13(1), 1.

[26] Jabessa, S. (2015). Multilevel Analysis of Acute Respiratory Infection Symptoms among under Five Children in Ethiopia. Journal of Biometrics \& Biostatistics, 6(4), 1.

[27] Keter, P., Mbakaya, C., Gikunju, J., \& Mutai, J. (2015). Knowledge, Perceptions and Practices of Mothers in Relation to Childhood Pneumonia at Kapsabet District Hospital in Nandi County, Kenya. - Google Search. Retrieved August 16, 2016.

[28] Noordam, A. C., Carvajal-Velez, L., Sharkey, A. B., Young, M., \& Cals, J. W. (2015). Care seeking behavior for children with suspected pneumonia in countries in subSaharan Africa with high pneumonia mortality. PloS one, 10(2), e0117919.

[29] Fatmi, Z., \& White, F. (2002). A comparison of 'cough and cold' and pneumonia: risk factors for pneumonia in children under 5 years revisited. International Journal of Infectious Diseases, 6(4), 294-301. 
[30] Bbaale, E. (2011). Determinants of diarrhoea and acute respiratory infection among under-fives in Uganda. The Australasian medical journal, 4(7), 400.

[31] Dadi, A.F., Kebede, Y. and Birhanu, Z. (2014) Determinants of Pneumonia in Children Aged Two Months to Five Years in Urban Areas of Oromia Zone, Amhara Region, Ethiopia. Open Access Library Journal, 1: $1044 .$.

[32] Azad, K. M. A. K. (2009). Risk factors for acute respiratory infections (ARI) among under-five children in Bangladesh. Journal of Scientific Research, 1(1), 72-81.

[33] Tilahun Ferede Asena. Multilevel modelling of modern contraceptive use among Rural and Urban population of Ethiopia. American Journal of Mathematics and Statistics. 2013;3(1):1-16.

[34] Briggs, D. (2003). Making a difference: Indicators to improve children's environmental health (pp. 1-17). Geneva: World Health Organization.

[35] Ghimire, M., Pradhan, Y. V., \& Maskey, M. K. (2010). Community-based interventions for diarrhoeal diseases and acute respiratory infections in Nepal. Bulletin of the World Health Organization, 88, 216-221. 